\title{
Cell-Size Control
}

\author{
Amanda A. Amodeo and Jan M. Skotheim \\ Department of Biology, Stanford University, Stanford, California 94305 \\ Correspondence: skotheim@stanford.edu
}

Cells of a given type maintain a characteristic cell size to function efficiently in their ecological or organismal context. They achieve this through the regulation of growth rates or by actively sensing size and coupling this signal to cell division. We focus this review on potential size-sensing mechanisms, including geometric, external cue, and titration mechanisms. Mechanisms that titrate proteins against DNA are of particular interest because they are consistent with the robust correlation of DNA content and cell size. We review the literature, which suggests that titration mechanisms may underlie cell-size sensing in Xenopus embryos, budding yeast, and Escherichia coli, whereas alternative mechanisms may function in fission yeast.

\section{INTRODUCTION: CELLS MAINTAIN A CHARACTERISTIC CELL SIZE}

$\mathrm{C}$ ells size varies greatly depending on cell type and species. Among eukaryotic cells, $\sim 1$-mm frog oocytes (Wallace et al. 1981) are 1000 times larger in diameter than $\sim 1-\mu \mathrm{m}$ phytoplankton, a billion-fold difference in volume (Palenik et al. 2007). Many soil bacteria are $\sim 250 \mathrm{~nm}$ in diameter (Luef et al. 2015), whereas the largest prokaryote, Thiomargarita namibiensis, can be larger than $>100 \mu \mathrm{m}$ (Schulz et al. 1999). Even within an organism, cells of different types may be of very different sizes: human blood cells are tiny $(<10 \mu \mathrm{m})$ compared with $>1$-m-long neurons.

For each type of cell, efficient function depends on appropriate size. Unicellular organisms need to proliferate in a variety of environmental contexts that exert selective pressures on cell size. Indeed, it has recently been shown that cell size correlates precisely with fitness for bacteria growing in a fluctuating environment (Monds et al. 2014). For the larger unicellular organisms, surface transport may be limiting for cell growth. Maximum transport rates of nutrients across the cell surface are expected to scale with surface area, whereas the metabolic requirements likely scale with volume. Thus, in the case of nutrient limitation, the surface-tovolume ratio may exert a selective pressure for smaller size. Consistent with this idea, the availability of atmospheric oxygen, which varies more than twofold on geological time scales, appears to be a major constraint on the cell size of $\sim 1$-mm-diameter unicellular, marine protist, foraminifera (Payne et al. 2012, 2013). In addition, there may be constraints on the ratio of parent and offspring size in foraminifera, suggesting that there may be a limited range of cell sizes that can be controlled by a specific genome (Caval-Holme et al. 2013).

Editors: Rebecca Heald, Iswar K. Hariharan, and David B. Wake

Additional Perspectives on Size Control in Biology: From Organelles to Organisms available at www.cshperspectives.org

Copyright (C) 2016 Cold Spring Harbor Laboratory Press; all rights reserved; doi: 10.1101/cshperspect.a019083

Cite this article as Cold Spring Harb Perspect Biol 2016;8:a019083 
A.A. Amodeo and J.M. Skotheim

In contrast to unicellular organisms, cells within multicellularorganisms experience much more constant environments, wherein nutrients are unlikely to be limiting. However, the function of these cells still strongly depends on their size. For example, blood cells must maintain a sufficiently small size to allow them to pass through capillaries, and neurons must span great distances to transduce signals down the lengths of limbs. Furthermore, defects in cell size are associated with diseases, such as Lhermitte-Duclos disease, in which increased cerebellar granule cell size leads to seizures and eventual death (Kwon et al. 2001).

In some multicellular organisms, cell size can influence organ and organism size. This scaling is absolute in Caenorhabditis elegans, in which the cell number is fixed and perturbations to cell size result in proportional changes in or- gan and organism size (Irle and Schierenberg 2002; Cook and Tyers 2007; Watanabe et al. 2007). However, in a large number of species, such as the tiger salamander, alterations to cell size can be compensated for by changes in cell number to preserve organ size (Fig. 1) (Fankhauser 1945). In addition, forcing proliferation in fly wing imaginal discs alters cell size, but triggers sufficient apoptosis to maintain organ size (Neufeld et al. 1998). We refer the reader to Roth and Walkowiak (2015) and Penzo-Méndez and Stanger (2015) for further discussion of organ size regulation.

Because of functional constraints, cells are under pressure to maintain a characteristic size for their given type. To accomplish this size homeostasis, growth and division must be coupled. For example, yeast grown in nutrientpoor conditions adjust their cell-cycle duration
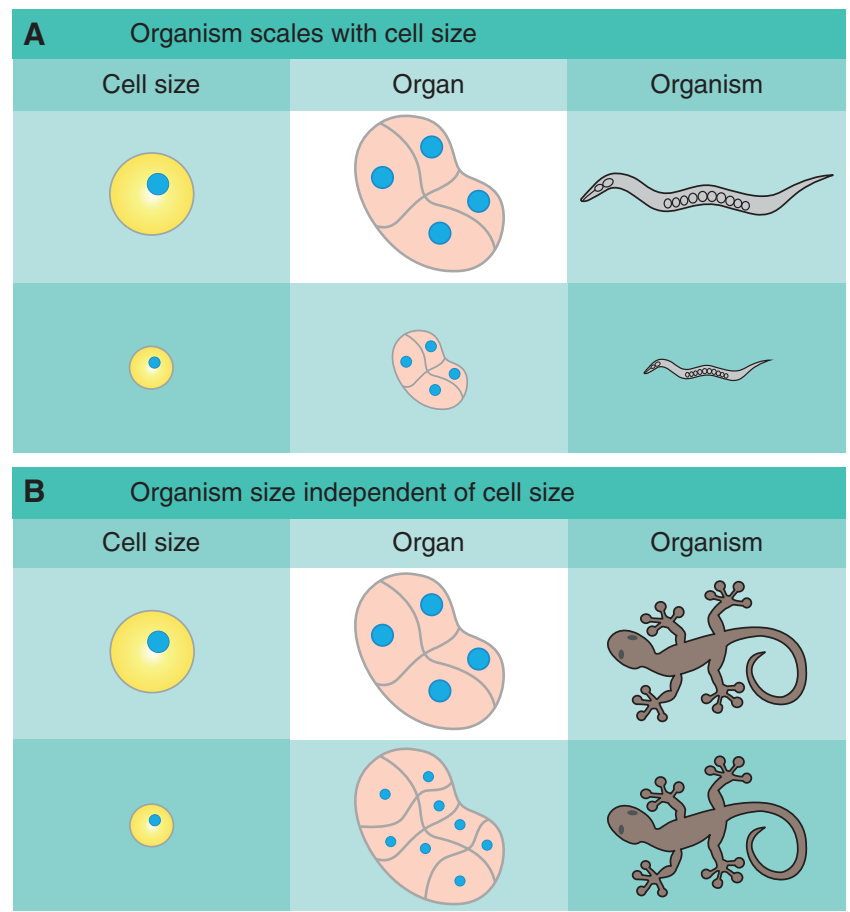

Figure 1. Influence of cell size on organ and organism size. In multicellular organisms, cell size can interface with organ and organism size in one of two ways. $(A)$ If the number of cells is fixed, changes in cell size will lead to changes in organ and, subsequently, organism size, as in C. elegans. (B) If organ size is regulated independently of cell size, changes in cell size will be compensated for by changes in cell number, resulting in a constant organ and organism size, as happens in salamanders. A mix of both mechanisms is also possible in which cell size affects organ size, but is partially compensated for by changes in cell number. 
to accommodate for slower growth, so that cells divide at roughly similar sizes as in nutrient-rich environments (Jorgensen et al. 2002; Di Talia et al. 2007, 2009; Brauer et al. 2008). This sizedependent cell-cycle progression implies that cells have a way of sensing their own size. Yet, how size homeostasis is maintained has remained elusive. Certainly, it is not necessary that cells measure their volume per se and we interpret the word "size" more liberally to encompass a range of correlated properties, such as total protein, ribosome content, or biosynthetic capacity (Carlson et al. 1999). The specific property measured may well be distinct in different organisms and cell types, which will have implications for the specific molecular mechanism used. Here, we review recent advances and discuss a conceptual framework that potentially links a large class of cell-size questions.

\section{THE RELATIONSHIP BETWEEN GROWTH AND SIZE CONTROL}

At its most fundamental, cell-size control within a specified time interval ensures that larger cells grow proportionally less than smaller cells. This means that growth and the cell-division cycle must be coordinated. In theory, this regulation could take place at any point in the cell cycle, which is conventionally divided into four distinct phases. The first is a growth period immediately following the previous division called $\mathrm{G}_{1}$. The second is the phase in which the DNA is synthesized, known as $\mathrm{S}$ phase. The third is another post $-S$ phase growth period called $G_{2}$, and the fourth is mitosis or $\mathrm{M}$ phase, in which the DNA is packaged and separated into two daughter cells (Fig. 2). Importantly, size control does not have to completely compensate for initial cell-size differences. Rather, size control is a quantitative feature whose strength in an interval can be measured (Wheals 1982; Tyson and Diekmann 1986; Sveiczer et al. 1996; Di Talia et al. 2007, 2009). For example, weak size control might require multiple cell-division cycles to return an initially aberrantly large or small cell to the characteristic size, whereas strong size control could do this in one cycle.

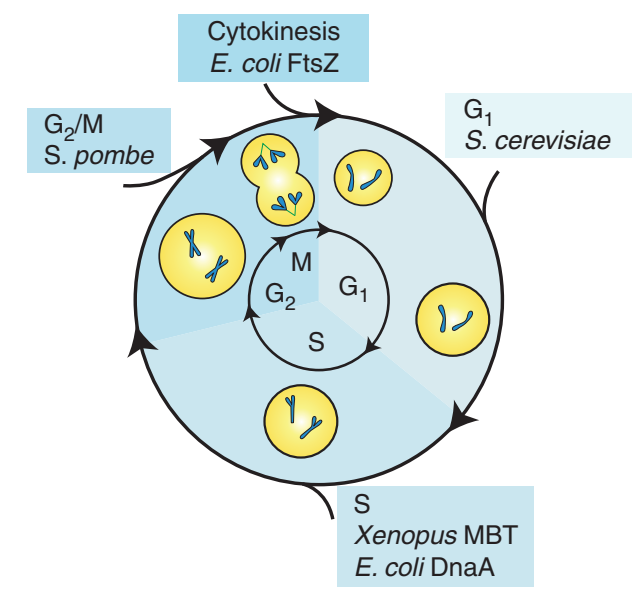

Figure 2. The cell cycle and cell size. The cell cycle is divided into four phases. $G_{1}$ is a growth phase immediately following the previous division. $S$ phase is when the DNA is replicated. $G_{2}$ is a second growth period followed by mitosis or $\mathrm{M}$ phase when the DNA is condensed and partitioned into the daughter cells. The relevant phases for cell-size control in different systems discussed in the text are as marked. MBT, midblastula transition.

For some cell-growth dynamics, cell-size homeostasis can be maintained without a cellsize sensor. All that is required for size homeostasis is that smaller cells grow proportionally more than larger cells in a cell cycle so that size variation is reduced in the next generation. For example, in the case of a constant rate of linear growth, the cell size, $V$, will increase at a constant rate so that $d V / d t=C$. In this case, specifying the duration of the cell cycle determines the amount of growth so that, in proportion, smaller cells grow more than larger cells and the population approaches a mean size without any specific size-sensing mechanism (Conlon and Raff 2003). Thus, some cellgrowth dynamics do not require a cell-size measurement to maintain size homeostasis.

Other growth dynamics do necessitate a size measurement. One such example is exponential growth, in which the rate of growth is proportional to cell size: $d V / d t=\alpha V$. Here, a timer mechanism will not maintain size homeostasis because cells born larger would grow proportionally more during a specified period. Fluctu- 
A.A. Amodeo and J.M. Skotheim

ations in division times will then result in a progressively wider size distribution unless the cells use a size-sensing mechanism to limit cellcycle duration in larger cells (Tyson and Hannsgen 1985).

The importance of the dynamics of cell growth for size control has motivated many studies (Mitchison 2003; Ginzberg et al. 2015). In the case of budding yeast, Escherichia coli and Caulobacter crescentus, cell growth in an unperturbed cell cycle is likely close to exponential, as supported by both single-cell analyses using fluorescence time-lapse microscopy and microchannel resonators, as well as classical bulk experiments using radioactive labeling (Elliott and McLaughlin 1978; Di Talia et al. 2009; Godin et al. 2010; Campos et al. 2014; Osella et al. 2014). However, other groups have argued that the budding yeast $G_{1}$ growth is closer to linear based on estimates of cell volume using time-lapse phase contrast microscopy (Ferrezuelo et al. 2012), and that growth rates are altered by cell-cycle phase (Goranov et al. 2009). For a more complete discussion of yeast size control and growth, see Turner et al. (2012). Fission yeast growth is certainly less likely to be exponential as reviewed in Mitchison (2003), and growth in metazoan cells is almost certainly not (Son et al. 2012; Kafri et al. 2013; Sung et al. 2013). The clear deviation from exponential growth in mammalian and other cells does not imply that these cells do not use a size sensor. In cases in which size sensors are not strictly necessary, they may still be desirable to enhance size control to keep the cell closer to the optimal range of sizes for proliferation and function. Thus, the only way to determine if cell-size sensors are operating in a given cell type is to identify the molecular mechanisms regulating size.

\section{MANY POTENTIAL SIZE-SENSING MECHANISMS}

Active regulation of cell-cycle progression in response to cell size requires that cells have a method to accurately measure their size. Cells might accomplish size measurement through a geometric mechanism if there is little cell-to-cell variation in their geometry. A geometric mech- anism seems unlikely in amoeboid cells or in the microvilli-containing cells of the small intestine, but is much more plausible in rod-shaped bacteria and fission yeast, which grow in a wellspecified geometry along a single dimension. One means of determining size geometrically would be to measure the ratio of surface area to volume because, for many geometries, surface area increases less rapidly than volume. A related possibility is that cells might sense cell length via intracellular gradients of cell-cycle regulators (Martin and Berthelot-Grosjean 2009; Moseley et al. 2009). In this case, segregation of critical components to designated subcellular locations would allow the cell to assess the distance between these compartments as a proxy for cell size (Fig. 3A).

In multicellular organisms, external landmarks, such as tissue edges or junctions with target cells, could be used to constrain cell growth. For example, some neurons grow until they make contact with their target (Fig. 3B) (Guthrie 2007). However, this mechanism requires that an external pattern is already in place and cannot generate size control de novo, so we do not focus our attention on this mechanism in this review.

Finally, cells could measure their volume directly by titration of a constant-concentration sensor molecule against a fixed internal "yardstick." This mechanism requires that the production of the volume sensor be proportional to cell growth and that there be a fixed yardstick to measure, that is, titrate against (Fig. 3C). Here, we explore the relevance of titration mechanisms in several biological contexts.

\section{CELL SIZE CORRELATES WITH DNA CONTENT}

One of the earliest and most consistent observations about cell size is its relationship to ploidy. In the early 1900s, Theordor Boveri produced sea urchin embryos in a range of ploidies by manipulating the conditions of fertilization. Haploid embryos divided more than diploid embryos and, thereby, maintained a consistent final ratio of DNA to cytoplasm. In further experiments, he created triploid and tetraploid 
Cell-Size Control

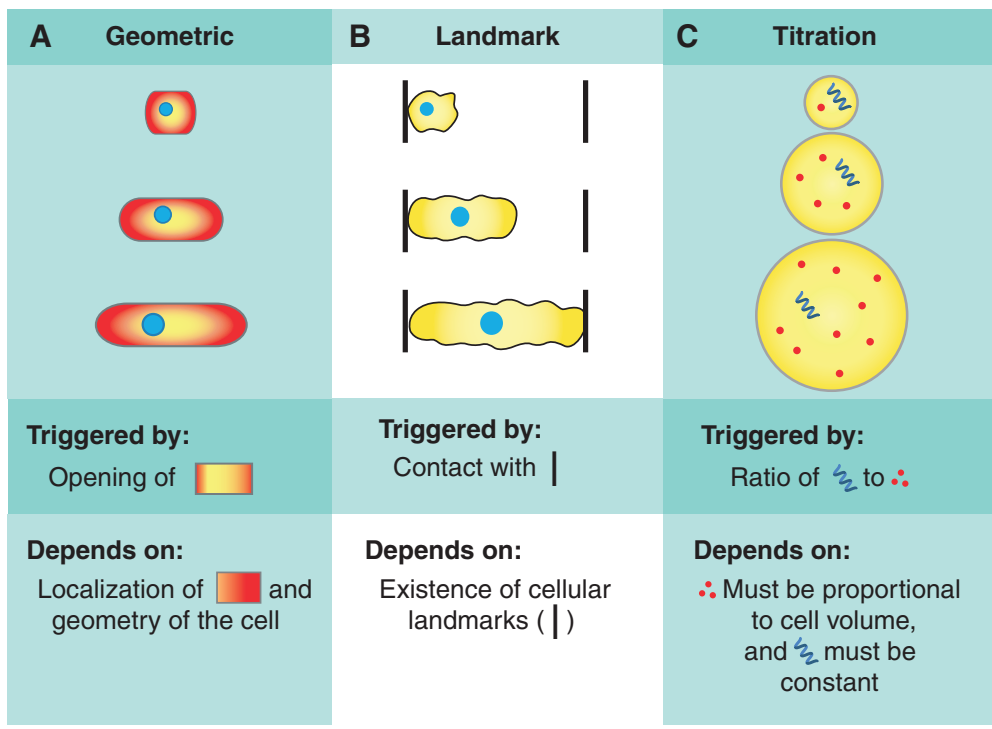

Figure 3. Cell-size measurement mechanisms. Cells can potentially sense their size via a number of different mechanisms, including $(A)$ aspects of their cell geometry, such as surface area to volume or cell length, via intracellular gradients, $(B)$ extracellular landmarks, and $(C)$ titration of a constant concentration regulator, whose amount scales with cell size against a fixed "yardstick" to measure cell size.

embryos through multiple fertilizations. In these embryos, spindle abnormalities caused an uneven distribution of chromosomes so that not all cells received integer multiples of the genome. In all cases, Boveri observed that the number of divisions within a given sector of the embryo was affected by the DNA content that sector received in the first cleavage. By the pluteus larval stage, urchin cells that had received more DNA were proportionally larger than those that had received less, which indicated that the relationship extended beyond a simple size scaling with ploidy (Wilson 1926).

The relationship between cell size and ploidy holds well beyond the embryo. Viable adult salamanders can be created from haploid to pentaploid. In all cases, the size of the cells within their tissues increases or decreases correspondingly, although compensatory variations in cell number maintain a relatively invariant total organism size (Fankhauser 1945). This relationship is true in unicellular eukaryotes as well. For example, the cell size of budding yeast correlates with ploidy from haploid to hexaploid (Mortimer 1958; Mayer et al. 1992).
Developmentally regulated changes in ploidy correlate with cell size in numerous large cell types. Often, as in the case of fly salivary gland and the mammalian trophoblast, cells increase their ploidy by undergoing rounds of endoreduplication. In many cases, such as the wing scale cells in the moth, Ephestia, the degree of endoreduplication correlates with cell size within a tissue (Fig. 4B) (Edgar and Orr-Weaver 2001). Similarly, as the land-slug Limax grows over its lifetime, it increases the size of the neurons within its brain through endoreduplication (Yamagishi et al. 2011). A very tight relationship has been shown between DNA content and cell size in the green algae, Eudorina (Tautvydas 1976). The filamentous yeast, Ashbya, also contains many copies of its genome within a single cytoplasm. In this case, individual nuclei appear to be carefully spaced within the growing cells to retain a relatively constant local and global ratio of DNA to cytoplasm (Nair et al. 2010; Anderson et al. 2013).

Endoreduplicative cell cycles increase ploidy by entering a relatively normal $S$ phase, but then skip cytokinesis, resulting in a doubling of the 

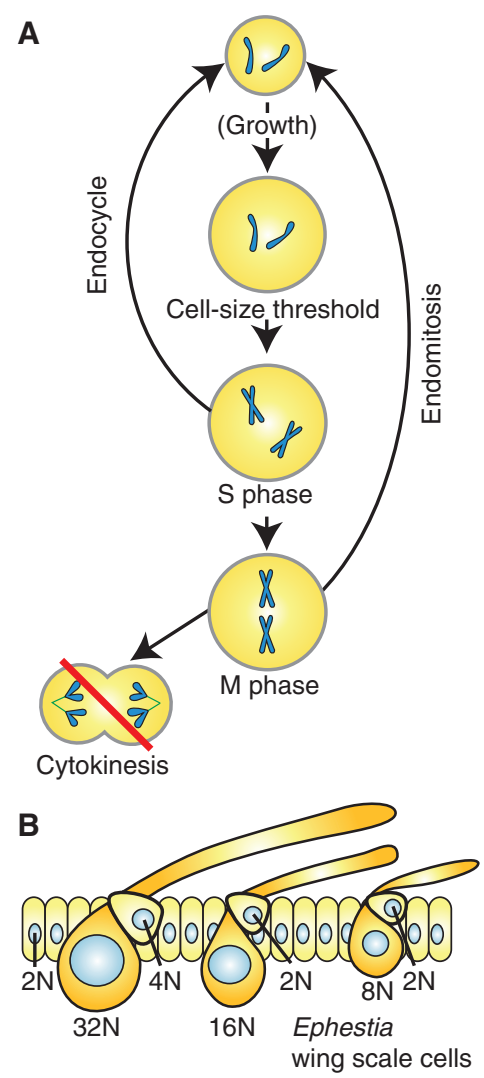

Figure 4. Endoreduplication increases cell size. DNA content correlates with cell size in a variety of organisms and contexts. $(A)$ Endoreplicative cell cycles are similar to mitotic cycles without cytokinesis. Endocycling cells proceed directly from an $\mathrm{S} / \mathrm{G}_{2}$-like state to another $G_{1}$, whereas endomitotic cells undergo a partial mitosis but abort before cytokinesis. (B) The wing scale cells of the moth, Ephestia, vary in ploidy from $8 \mathrm{~N}$ to $32 \mathrm{~N}$ with higher ploidy cells being larger than lower ploidy cells (modified from data in Edgar and Orr-Weaver 2001).

DNA content with each iteration. This process can be repeated a large number of times resulting in very high ploidies (up to $24,000 \mathrm{C}$ in the case of some plant endosperms) (Traas et al. 1998). Endoreduplicating cell cycles are not simply unregulated or prolonged $S$ phases. Instead, these cells go through a normal $G_{1}$ and $S$ phase in which the DNA is only replicated once. They then either proceed directly from $\mathrm{G}_{2}$ into another $\mathrm{G}_{1}$-like state (called an endocycle), or they enter into mitosis, but abort before cyto- kinesis is completed and return to the $\mathrm{G}_{1}$-like state (called an endomitosis) (Fig. 4A) (Zielke et al. 2013). In both cases, the activity of conventional $\mathrm{M}$-phase regulators is absent or prematurely lost. However, $G_{1} / S$ regulation in endoreplicating cells appears to be broadly similar to what is found in conventional mitotic cell cycles (Edgar and Orr-Weaver 2001). This implies that, if a mechanism to measure cell size relative to DNA content were operable at the $\mathrm{G}_{1} / \mathrm{S}$ transition, it might also explain the ploi$\mathrm{dy}$-size relationship observed for endoreduplicated cell types.

We note that the relationship between DNA content and cell size is not only true within single species, but seems to be constant across most eukaryotes, which encompasses more than six orders of magnitude in cell size. A similar correlation between cell size and DNA content has also been observed in prokaryotes, although the DNA content increases much more slowly with cell size than in eukaryotes (Gregory 2000; Cavalier-Smith 2001). Note that this does not imply that the mechanism of size measurement is identical in all clades, but rather that there exist selective pressures that maintain a roughly linear relationship between DNA content and cell size across eukaryotes.

\section{A TITRATION SENSOR REGULATES THE MIDBLASTULA TRANSITION IN Xenopus}

As noted by Boveri (discussed above), DNA content strongly affects cell size during early development. In many fast-developing species, cell division is uncoupled from cell growth during the early cleavage divisions. These embryos typically start out with very large cells that undergo rapid divisions without growth phases. Because of the lack of growth phases, the total cytoplasmic volume remains constant, whereas the cell size decreases exponentially. These divisions are also unusual in that they lack cell-cycle checkpoints and are transcriptionally inactive. These rapid cell cycles continue for a set number of divisions until the onset of a developmental transition called the midblastula transition (MBT). At the MBT, the cell cycle lengthens 
with the addition of growth phases, checkpoints become active, and the zygotic genome initiates large-scale transcription (Fig. 5A) (Masui and Wang 1998).

Early experiments on the MBT in frogs identified the DNA-to-cytoplasmic ratio as critical for its regulation. A large body of experimental evidence shows that alteration of this ratio results in corresponding changes to the number of rapid cell cycles before the MBT. Haploid embryos undergo the MBT one cell cycle later (Masui and Wang 1998). Polyspermic embryos and embryos injected with plasmid DNA undergo premature cell-cycle lengthening and transcriptional activation, respectively (Newport and Kirschner 1982a,b). Perhaps most convincingly, embryos that are tied in half with an unequal distribution of DNA show premature cell-cycle lengthening on the half of the embryo with increased DNA and delayed cell-cycle lengthening in the half with reduced DNA (Newport and Kirschner 1982b). This experiment is especially compelling because the two halves of the embryo were fertilized at the same time and the nuclei have undergone the same number of divisions. The only difference between the two sides is their DNAto-cytoplasm ratio. These findings lead to the hypothesis that the embryo begins development with a relatively constant store of maternally deposited inhibitor, which is titrated against the exponentially increasing amount of DNA (Newport and Kirschner 1982b). Once a critical threshold is met, the embryo initiates transcription and the MBT. Therefore, sensing the ratio of cytoplasm per genome is one way of sensing cell size, the MBT can be viewed as a size-sensing problem. Here, the amount of regulator is proportional to cell size, which is measured by titration against the amount of DNA in a cell. This mechanism is an elegant way to measure cell size independent of cell geometry or external cues.

Recent work has sought to identify factor(s) that are titrated against DNA to set the threshold for the MBT in frogs and thereby support the titration model. Three different groups of factors have been proposed. The first is the phosphatase PP2A, which appears to be limiting for S-phase progression in vitro at DNA concentrations close to those found at the MBT. For increasing DNA-to-cytoplasm ratios, $\mathrm{S}$ phase slows without addition of exogenous PP2A (Murphy and Michael 2013). Similarly, addition of a cocktail of four DNA replication factors, Cut5, RecQ4, Treslin, and Drf1, which become unstable at the MBT, can lead to additional rapid cell cycles in vitro and in embryos (Fig. 5C) (Collart et al. 2013). Our work suggests that core histones $\mathrm{H} 3$ and $\mathrm{H} 4$ are directly titrated against DNA to activate transcription in vitro and in vivo (Fig. 5B) (Amodeo et al. 2015). Alteration of histone concentration in vitro shifts the amount of DNA required for transcriptional activation. Moreover, an $\sim 50 \%$ reduction of $\mathrm{H} 3$ in vivo results in the MBToccurring precisely one cell cycle earlier, consistent with histone-DNA titration being responsible for triggering the MBT. In addition to these proposed titrated components, nuclear import factors and resulting nuclear size has recently been suggested to regulate MBT timing (Jevtic and Levy 2015). This observation suggests that nuclear concentration of inhibitory factors may be critical for cell-size sensing in the early embryo. Overall, these potentially overlapping mechanisms provide good evidence that the MBT is controlled by a cytoplasm-to-DNA ratio mechanism resulting from the titration of some constant concentration regulator(s) against the DNA.

\section{TITRATION OF CYCLINS IN BUDDING YEAST}

Cell-size control can be most directly studied in unicellular rather than multicellular organisms because cell size is more easily measured and the number of cell types more limited. For this reason, the yeasts Saccharomyces cerevisiae and Schizosaccharomyces pombe have been favorite models for the study of cell-size regulation.

Budding yeast divide asymmetrically, and size control occurs in the smaller daughter cells primarily in $\mathrm{G}_{1}$ (Di Talia et al. 2009). Smaller cells spend more time in $G_{1}$, but this size control is imperfect because variations in size are not eliminated in a single cell cycle (Johnston 1977; 
A.A. Amodeo and J.M. Skotheim

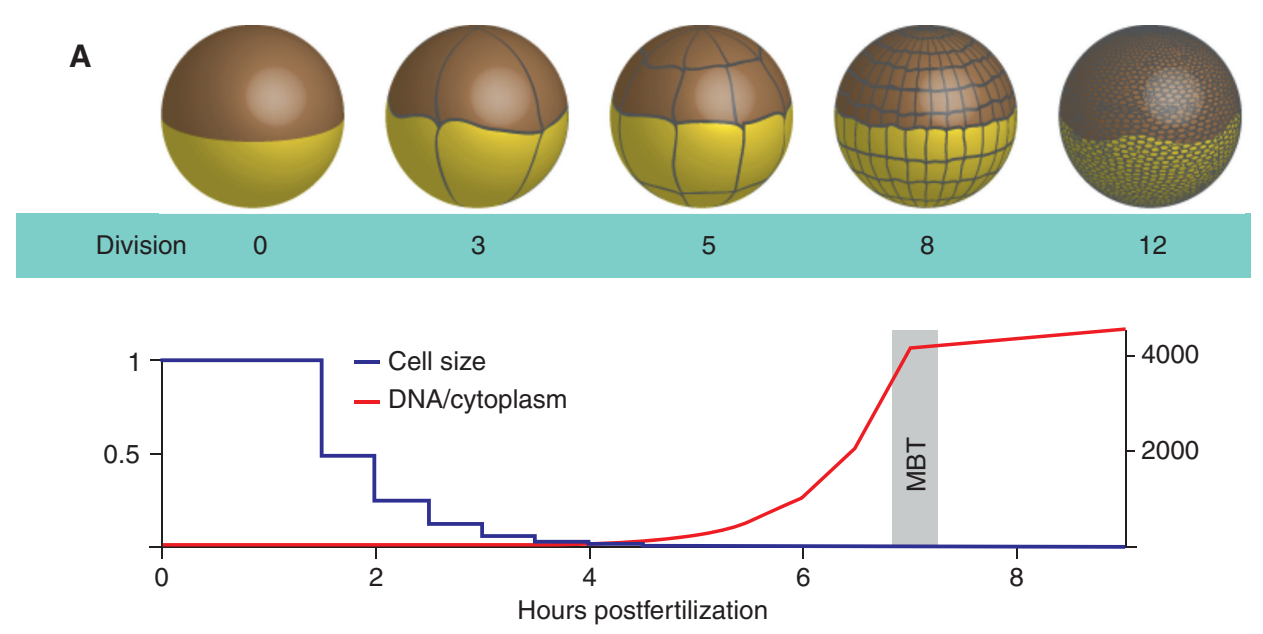

B Titration of histones and ZGA

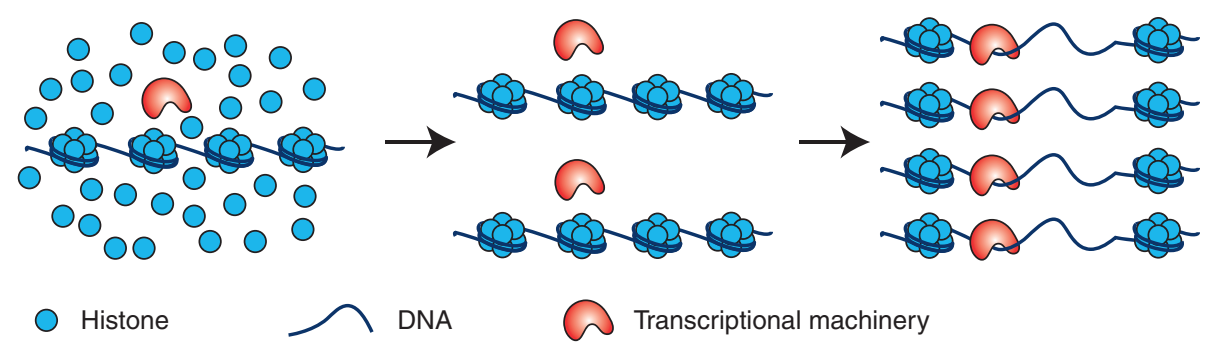

C Titration of replication factors and S phase

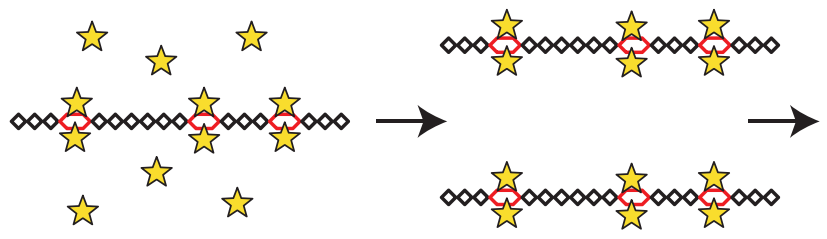

irs Replication factors

$\bigcirc$ Origin of replication

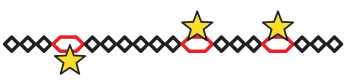

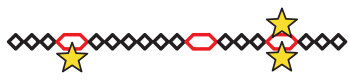

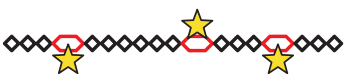

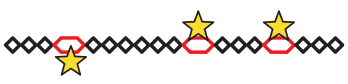

$\infty$ DNA

Figure 5. Midblastula transition (MBT) controlled by titration of regulators against DNA. $(A)$ During the early cleavage cycles, Xenopus embryos divide without growth, resulting in an exponentially decreasing cell size and an exponentially increasing ratio of DNA to cytoplasm. (B) Titration of constant-concentration histones against the exponentially increasing quantity of DNA sets the timing of zygotic genome activation (ZGA) by inhibiting transcription below the threshold DNA concentration. When DNA concentration reaches a critical threshold, inhibition is relieved and transcription becomes activated (Amodeo et al. 2015). (C) Titration of key replication factors against DNA sets the timing of S-phase lengthening. When DNA concentration becomes sufficiently high, the available replication factors are no longer able to efficiently trigger $S$ phase, resulting in a longer cell cycle (Collart et al. 2013). 
Di Talia et al. 2007). Progression through $G_{1}$ is initiated by the cyclin Cln3. Cyclins are canonical cell-cycle regulators whose levels often oscillate during the cell cycle to coordinate the activity of their partner kinases, the cyclin-dependent kinases or CDKs and thereby promote cell-cycle progression. Cln3 binds and activates CDK1 to partially inactivate the transcriptional inhibitor Whi5 (Bertoli et al. 2013). Inactivation of Whi5 relieves inhibition of the transcription factor SBF, whose target genes include the additional cyclins, Cln1 and $\mathrm{Cln} 2$. These two cyclins complete inactivation of Whi5 via a positive feedback loop, which drives further cellcycle progression (Eser et al. 2011). Activation of this feedback loop ensures irreversible commitment to cell-cycle progression (Skotheim et al. 2008; Charvin et al. 2010; Doncic and Skotheim 2013). Interestingly, the levels of the upstream rate-limiting cyclin Cln3 oscillate weakly through the cell cycle compared with other cyclins and may be at a constant concentration during mid $\mathrm{G}_{1}$ (Tyers et al. 1993). Therefore, $C \ln 3$ might be used to sense cell size via a titration mechanism.

Cln3 may be titrated against genomic DNA itself, or against specific binding sites. Consistent with the latter possibility, cell size was shifted by a high-copy plasmid containing multiple SBF-binding sites in a Cln3-Whi5-dependent manner (Wang et al. 2004). In either case, Cln3-Cdk complexes, whose number is likely proportional to cell size, would be titrated against a constant DNA yardstick. Consistent with this model, a recent study constitutively expressing $\mathrm{Cln} 3$ at different levels showed that the concentration of $\mathrm{Cln} 3$ inversely correlated with $\mathrm{G}_{1}$ length (Liu et al. 2015). However, the implications of these Cln3-titration conjectures remain largely untested.

Although the proposal of titrating $\mathrm{Cln} 3$ against the genome is attractive because of the fixed genome size during $G_{1}$, this is not the only possibility. Cln3 could potentially be titrated against another protein whose abundance did not scale with cell size to produce a cell-size measurement (Fantes et al. 1975). The majority of yeast proteins are found at relatively constant concentrations and, thus, their total amounts scale linearly with volume (Newman et al 2006). However, transcription of several genes, including many cell-surface-related proteins, is not proportional to cell size so that larger cells have lower messenger RNA (mRNA) concentrations for these specific targets (Wu et al. 2010). Thus, the proteins encoded by this set of genes are expected to be at lower concentrations in larger cells. One of these nonscaling genes could therefore serve as a titrated counterpart to $\mathrm{Cln} 3$ to affect $\mathrm{G}_{1}$ size control. Indeed, it was recently shown that the synthesis of the cell-cycle inhibitor Whi5 does not scale with size (Schmoller et al. 2015). This results in smaller-born daughter cells beginning the cell cycle with higher concentrations of Whi5. Because the synthesis of Whi5 is restricted to the $S / G_{2} / M$ phase of the cell-division cycle, cell growth dilutes Whi5 in $G_{1}$ to trigger progression into the cell cycle.

An alternate model for cell-size control in budding yeast posits a mechanism that prevents Cln3 nuclear entry below a threshold cell-size or size-dependent growth rate (Ferrezuelo et al. 2012). In this model, switch-like translocation of $\mathrm{Cln} 3$ results from a positive feedback loop based on the mutual inhibition of $\mathrm{Cln} 3$ and Whi7, a Whi5 paralog localized to the endoplasmic reticulum (Yahya et al. 2014). The chaperone protein, Ydj1, and the posttranscriptional regulator, Whi3, may also be involved in $\mathrm{Cln} 3$ retention outside the nucleus (Gari et al. 2001; Wang et al. 2004; Verges et al. 2007). However, the size-dependent retention of $\mathrm{Cln} 3$ is still under debate. Other groups have failed to observe Cln3 outside the nucleus, although this might be caused by the low number of $\mathrm{Cln} 3$ molecules (Miller and Cross 2000; Edgington and Futcher 2001; Cai and Futcher 2013). Finally, even if the Cln3-import model is correct, it does not yet easily explain how cell size or growth rate is sensed to trigger $\mathrm{Cln} 3$ translocation.

Although $G_{1}$ appears to contain the major size checkpoint in budding yeast, evidence also exists for $\mathrm{S} / \mathrm{G}_{2} / \mathrm{M}$ size regulation. Cells that are experimentally forced through $G_{1}$ by overexpression of $G_{1}$ cyclins maintain size homeostasis. In this case, cells that are smaller when entering $S$ phase spend slightly more time in $S$ / $\mathrm{G}_{2} / \mathrm{M}$ and, thereby, partially compensate for 
A.A. Amodeo and J.M. Skotheim

reduced $\mathrm{G}_{1}$ growth (S Di Talia, pers. comm.). This suggests the possibility that the network regulating entry to mitosis might also contribute to size homeostasis, in addition to its more defined role in the morphogenesis checkpoint (Harvey and Kellogg 2003; McNulty and Lew 2005; Howell and Lew 2012; Zapata et al. 2014).

\section{TITRATION OF DnaA IN E. Coli}

Titration of regulatory molecules against a cellular component whose size is invariant with growth has been proposed to regulate specific points of the bacterial cell cycle (Chien et al. 2012). Whereas any point in the cell cycle can potentially be regulated via a size checkpoint, two specific points of control have been identified through studies of E. coli and Bacillus subtilis. Bacterial size control has been reported to impact the onset of DNA replication and cell division. In both cases, a titration mechanism has been suggested as the basis of size-dependent, cell-cycle-progression signals (Donachie 1968; Teather et al. 1974; Chien et al. 2012).

To control replication, Donachie (1968) proposed that a constant concentration activator would accumulate at the origins of replication. In this model, a regulator whose number increases with cell size would titrate against the fixed number of origins to yield a size-dependent activating signal. Consistent with this model, cell size at the onset of replication in E. coli was similar regardless of birth size and growth rate. Even in the case of the fastest growing E. coli, in which mass doubling outpaces the duration of replication so that large cells contain multiple copies of partial genomes, replication is triggered at a constant size-to-origin ratio (Donachie 1968).

The most likely candidate for Donachie's titrated replication activator is DnaA, which binds cooperatively to origins to promote loading of the replication machinery (Kaguni 2006). Consistent with the DnaA-titration model, the size-to-origin ratio at replication initiation is sensitive to DnaA expression levels (LobnerOlesen et al. 1989). Furthermore, mutations affecting cell size at division, but not cell-growth
A

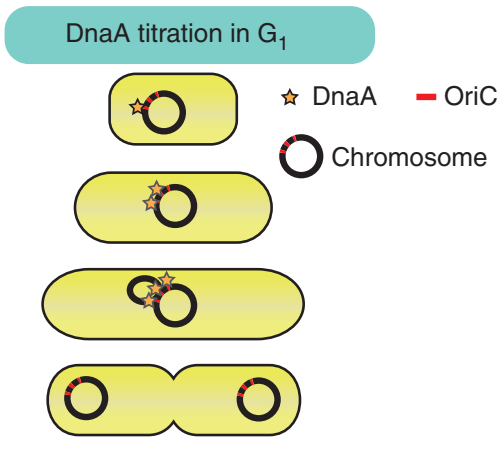

B
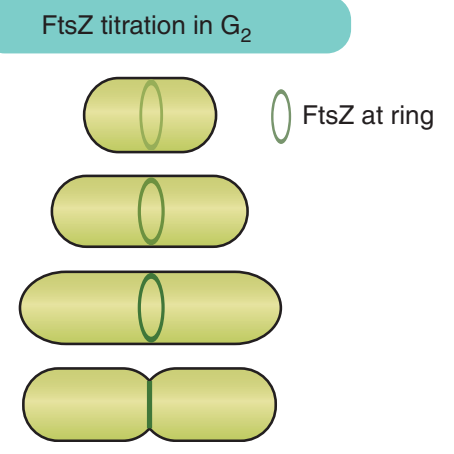

Figure 6. Proposed titration mechanisms for cell-size measurement in bacteria. (A) ATPase DnaA accumulates on origins of replication in a size-dependent manner until a critical threshold triggers replication. (B) FtsZ accumulates at the site of cytokinesis as the cell grows until reaching a threshold that triggers cytokinesis.

rate, do not change DnaA concentration or the size at which cells initiate replication. Mutations making cells twice as large lead to cells containing twice the amount of DNA (Hill et al. 2012). Taken together, this evidence suggests molecular titration as the most plausible mechanism for coupling cell size to the onset of DNA replication in E. coli (Fig. 6A).

In addition to coordinating $S$ phase with cell size, E. coli may also coordinate cell division with cell size (Chien et al. 2012). The accumulation of the constant concentration regulator FtsZ at the cytokinetic ring could function as a titration-based cell-size sensor (Teather et al. 1974; Chien et al. 2012). Because cell growth of rod-shaped bacteria maintains a constant width, the circumference at the midcell is constant. Thus, titration of FtsZ against the midcell perimeter could yield a size-dependent signal to 
initiate cytokinesis (Fig. 6B). Although titration models have an inherent appeal for the size-dependent control of replication and division in bacteria, they have been insufficiently tested and we refer the reader to Levin and Angert (2015) for caveats to these models.

Recently, it has been shown that $C$. crescentus, B. subtilis, and E. coli cells are not subject to strict cell-size regulation (Amir 2014; Campos et al. 2014; Jun and Taheri-Araghi 2015; Taheri-Araghi et al. 2015). Rather, for a particular bacterial species growing in a particular environment, all cells grow about the same amount during a division cycle independent of their size at birth. Thus, cell-size fluctuations are not compensated for in a single-cell cycle, but dampened over several division cycles. That several groups independently arrived at a phenomenological model based on a constant size increase per division cycle requires, at the very least, a reformulation of the existing bacterial DNA-based or cytokinetic ring-based titration models.

\section{GEOMETRIC SIZE SENSING IN FISSION YEAST}

Similar to $E$. coli, fission yeasts are rod shaped and grow by lengthening at a constant width so that volume is proportional to length (Mitchison 2003). It has been proposed that fission yeast use a spatial gradient of the mitotic inhibitor Pom 1 emanating from its poles to measure cell size geometrically via length (Martin and Berthelot-Grosjean 2009; Moseley et al. 2009). In this model, division ensues when the concentration of Pom 1 dips below a critical concentration at the midcell, which occurs at a specific cell length.

Pom 1 regulates the mitotic trigger network centered on the competing kinase and phosphatase pair, Wee1 and Cdc25, which regulates Cdk activity. Pom 1 inhibits the Wee1-inhibitory kinases, Cdr1 and Cdr2, which localize to specific nodes at the midcell (Deng and Moseley 2013). As a cell grows, the gradient in Pom 1 from the poles ensures that its concentration at the midcell decreases, which could allow Cdr1 and Cdr2 to inactivate Weel and thereby promote mitotic entry. Perturbations of the Pom 1 gradient result in both changes to the Cdr2 distribution and cell size (Martin and Berthelot-Grosjean 2009; Moseley et al. 2009; Hachet et al. 2011; Bhatia et al. 2013).

However, several recent results have begun to cast doubt on the gradient model. First, the length scale of the exponential Pom 1 gradient $(\sim 1.5 \mu \mathrm{m})$ appears to be too short to accurately measure the length of a $>10-\mu \mathrm{m}$ cell (Saunders et al. 2012). Second, the gradient has a difficult time explaining why the DNA-to-cytoplasm ratio is maintained in fission yeast cells of different ploidy and in temperature-sensitive cytokinesis mutants (Neumann and Nurse 2007). Third, in fission yeast mutants of different widths, volume at mitosis was more variable than area, suggesting a surface-area-based model (Pan et al. 2014). Finally, cell-size control occurs, albeit less effectively, in cells lacking regulation of Cdk1 by Wee1 and Cdc25, indicating that the Pom 1 pathway is certainly not the only size-control mechanism (Coudreuse and Nurse 2010; Wood and Nurse 2013).

\section{TITRATION-BASED CELL-SIZE SWITCHES}

To link growth and proliferation, size-sensing mechanisms regulate cell-cycle transitions, which are typically switch-like and associated with threshold-ultrasensitive responses. Switchlike transitions are used to ensure coordination of downstream responses. For example, switchlike increases in Cdk activity ensure the coherent transcription of $G_{1} / S$ phase regulators, the allor-none replication of the genome during $S$ phase, and the robust phosphorylation of mitotic targets (Georgi et al. 2002; Skotheim et al. 2008; Ferrell et al. 2009; Koivomagi et al. 2011; Yang et al. 2013).

Under some conditions, titration mechanisms can directly generate ultrasensitive responses (Buchler and Louis 2008). For example, titration with a high-affinity stoichiometric inhibitor can generate an ultrasensitive response curve. Consider two proteins $\mathrm{A}$ and $\mathrm{B}$ that bind to form an inactive complex $\mathrm{AB}$. The response can be characterized as the amount of active $A$ as a function of the total amount of A given a fixed 
amount of B. For high-affinity interactions with $B$, low amounts of A will be fully inactivated by $B$. However, for increasing amounts of $A$, the inhibitor B is eventually titrated out so that, above a threshold, the amount of active A increases rapidly. In the case of DNA-binding proteins, such as DnaA, high-affinity decoy sites could serve the purpose of stoichiometric inhibitors because these sites will be occupied before the relevant target site and, therefore, titrate out the regulator to create an ultrasensitive response (Kitagawa et al. 1996).

Although titration mechanisms can produce ultrasensitivity, they need not generate the switch themselves. Graded upstream signals can be converted downstream to produce a switch-like response. For example, positive feedback loops at the $G_{1} / S$ and $G_{2} / M$ transitions convert small changes in the upstream kinase input signal to dramatic increases in downstream kinase activity associated with the next cell-cycle phase (Pomerening et al. 2003; Skotheim et al. 2008). In the case of budding yeast, a graded $\mathrm{Cln} 3$ signal may be coupled via Whi5 to a $C \ln 1 / 2$ positive feedback to generate a sharp increase in Cdk activity. Thus, downstream switches can generate threshold responses, thereby alleviating any such requirement on the upstream size-dependent signal.

Additional pathways may tune size thresholds in response to different conditions (Baroni et al. 1994; Tokiwa et al. 1994; Jorgensen and Tyers 2004). A size threshold can be modulated by regulation of either the upstream size-dependent signal or by modification of feedback loop components that affect sensitivity to the upstream signal. This is consistent with observations of core signaling components producing a positive feedback-driven switch and more peripheral signaling pathways modifying the threshold to achieve condition-dependent responses (Sha et al. 2003; Justman et al. 2009; Doncic and Skotheim 2013).

Whether ultrasensitive or not, titrationbased size sensors are relatively easy to generate. All they require is one component that is produced proportionally to cell size and another that is constant. Many proteins fit the profile for the titrated molecule because the majority of proteins and RNAs are found at roughly constant concentration during the cell-division cycle. This is supported by the fact that $<20 \%$ of yeast and mammalian transcripts cycle (Spellman et al. 1998; Whitfield et al. 2002; Oliva et al. 2005). Furthermore, a genome-wide analysis of green fluorescent protein (GFP)-tagged open reading frames (ORFs) in budding yeast concluded that most of the variability in protein abundance arose from variations in cell size (Newman et al. 2006). This is a natural consequence of larger cells having more protein and that the proportions of most protein species remain relatively constant during cell growth. Any one of these "cell-cycle-independent" proteins could potentially be titrated against a constant yardstick to yield a size sensor.

Constant yardsticks are much less common within growing cells because, much like proteins, the majority of organelles scale with cell size (see Marshall 2015; Reber and Goehring 2015). For example, nuclear size relative to that of the cell shows little variation. The nuclear size in yeast is $\sim 8 \%-10 \%$ of cell size in a variety of mutants (Neumann and Nurse 2007; Zhao et al. 2008). In contrast to organelles scaling with cell size, DNA is a more promising yardstick candidate because its amount is fixed for all segments of the cell cycle except $S$ phase. Moreover, size scales with DNA content in many experimental and endogenous contexts as discussed above. Thus, most DNA-binding proteins could potentially be used as a size sensor. Although DNA may be the most likely yardstick, it is not the only possibility as the synthesis of some protein species is also not proportional to cell size (Wu et al. 2010). Indeed, recent work in budding yeast showed that the cell-cycle inhibitor Whi5 is present in similar numbers in large and small cells (Schmoller et al. 2015). The titration of Whi5 against the cell-cycle activator $\operatorname{Cln} 3$, whose synthesis scales with cell size, then results in size-dependent progression through $\mathrm{G}_{1}$.

Cell size is one of the most basic and defining features of a given cell type, yet the molecular mechanisms underlying its control have remained elusive. We are excited by recent work revisiting this long-standing problem. Here, we 
reviewed the current understanding of sizesensing mechanisms and highlighted the potential of titration-based mechanisms. However, because of the ease with which size-dependent signals might be generated by any constant concentration DNA-binding protein, we do not expect conservation of the specific regulatory molecules.

\section{ACKNOWLEDGMENTS}

We thank J. Turner for helpful comments on the review and B. French for aid in figure design. The National Institutes of Health (NIH) (R21HD073772; T32GM007276) and the Burroughs Wellcome Fund (Career Awards at the Scientific Interface, CASI) supported this work.

\section{REFERENCES}

${ }^{*}$ Reference is also in this collection.

Amir A. 2014. Cell size regulation in bacteria. Phys Rev Lett 112: 208102.

Amodeo AA, Jukam DJ, Straight AF, Skotheim JM. 2015. Titration of histones sets the DNA threshold for the onset of the mid-blastula transition in Xenopus. Proc Natl Acad Sci 112: E1086-E1095.

Anderson CA, Eser U, Korndorf T, Borsuk ME, Skotheim JM, Gladfelter AS. 2013. Nuclear repulsion enables division autonomy in a single cytoplasm. Curr Biol 23: 19992010.

Baroni MD, Monti P, Alberghina L. 1994. Repression of growth-regulated $G_{1}$ cyclin expression by cyclic AMP in budding yeast. Nature 371: 339-342.

Bertoli C, Skotheim JM, de Bruin RA. 2013. Control of cell cycle transcription during $\mathrm{G}_{1}$ and $\mathrm{S}$ phases. Nat Rev Mol Cell Biol 14: 518-528.

Bhatia P, Hachet O, Hersch M, Rincon SA, Berthelot-Grosjean M, Dalessi S, Basterra L, Bergmann S, Paoletti A, Martin SG. 2013. Distinct levels in Poml gradients limit Cdr2 activity and localization to time and position division. Cell Cycle 13: 538-552.

Brauer MJ, Huttenhower C, Airoldi EM, Rosenstein R, Matese JC, Gresham D, Boer VM, Troyanskaya OG, Botstein D. 2008. Coordination of growth rate, cell cycle, stress response, and metabolic activity in yeast. Mol Biol Cell 19: $352-367$.

Buchler NE, Louis M. 2008. Molecular titration and ultrasensitivity in regulatory networks. J Mol Biol 384: 11061119.

Cai Y, Futcher B. 2013. Effects of the yeast RNA-binding protein Whi3 on the half-life and abundance of CLN3 mRNA and other targets. PLoS ONE 8: e84630.

Campos M, Surovtsev IV, Kato S, Paintdakhi A, Beltran B, Ebmeier SE, Jacobs-Wagner C. 2014. A constant size ex- tension drives bacterial cell size homeostasis. Cell 159: $1433-1446$.

Carlson CR, Grallert B, Stokke T, Boye E. 1999. Regulation of the start of DNA replication in Schizosaccharomyces pombe. J Cell Sci 112: 939-946.

Caval-Holme F, Payne J, Skotheim JM. 2013. Constraints on the adult-offspring size relationship in protists. Evolution 67: $3537-3544$.

Cavalier-Smith T. 2001. Obcells as proto-organisms: Membrane heredity, lithophosphorylation, and the origins of the genetic code, the first cells, and photosynthesis. J Mol Evol 53: 555-595.

Charvin G, Oikonomou C, Siggia ED, Cross FR. 2010. Origin of irreversibility of cell cycle start in budding yeast. PLoS Biol 8: e1000284.

Chien AC, Hill NS, Levin PA. 2012. Cell size control in bacteria. Curr Biol 22: R340-R349.

Collart C, Allen GE, Bradshaw CR, Smith JC, Zegerman P. 2013. Titration of four replication factors is essential for the Xenopus laevis midblastula transition. Science 341: 893-896.

Conlon I, Raff M. 2003. Differences in the way a mammalian cell and yeast cells coordinate cell growth and cell-cycle progression. J Biol 2: 7.

Cook M, Tyers M. 2007. Size control goes global. Curr Opin Biotechnol 18: 341-350.

Coudreuse D, Nurse P. 2010. Driving the cell cycle with a minimal CDK control network. Nature 468: 1074-1079.

Deng L, Moseley JB. 2013. Compartmentalized nodes control mitotic entry signaling in fission yeast. Mol Biol Cell 24: $1872-1881$.

Di Talia S, Skotheim JM, Bean JM, Siggia ED, Cross FR. 2007. The effects of molecular noise and size control on variability in the budding yeast cell cycle. Nature 448: 947-951.

Di Talia S, Wang H, Skotheim JM, Rosebrock AP, Futcher B, Cross FR. 2009. Daughter-specific transcription factors regulate cell size control in budding yeast. PLoS Biol 7: e1000221.

Donachie WD. 1968. Relationship between cell size and time of initiation of DNA replication. Nature 219: 1077-1079.

Doncic A, Skotheim JM. 2013. Feedforward regulation ensures stability and rapid reversibility of a cellular state. Mol Cell 50: 856-868.

Edgar BA, Orr-Weaver TL. 2001. Endoreplication cell cycles: More for less. Cell 105: 297-306.

Edgington NP, Futcher B. 2001. Relationship between the function and the location of $\mathrm{G}_{1}$ cyclins in S. cerevisiae. J Cell Sci 114: 4599-4611.

Elliott SG, McLaughlin CS. 1978. Rate of macromolecular synthesis through the cell cycle of the yeast Saccharomyces cerevisiae. Proc Natl Acad Sci 75: 4384-4388.

Eser U, Falleur-Fettig M, Johnson A, Skotheim JM. 2011. Commitment to a cellular transition precedes genomewide transcriptional change. Mol Cell 43: 515-527.

Fankhauser G. 1945. Maintenance of normal structure in heteroploid salamander larvae, through compensation of changes in cell size by adjustment of cell number and cell shape. J Exp Zool 100: 445-455. 
A.A. Amodeo and J.M. Skotheim

Fantes PA, Grant WD, Pritchard RH, Sudbery PE, Wheals AE. 1975. The regulation of cell size and the control of mitosis. J Theor Biol 50: 213-244.

Ferrell JE Jr, Pomerening JR, Kim SY, Trunnell NB, Xiong W, Huang CY, Machleder EM. 2009. Simple, realistic models of complex biological processes: Positive feedback and bistability in a cell fate switch and a cell cycle oscillator. FEBS Lett 583: 3999-4005.

Ferrezuelo F, Colomina N, Palmisano A, Gari E, Gallego C, Csikasz-Nagy A, Aldea M. 2012. The critical size is set at a single-cell level by growth rate to attain homeostasis and adaptation. Nat Commun 3: 1012.

Gari E, Volpe T, Wang H, Gallego C, Futcher B, Aldea M. 2001. Whi3 binds the mRNA of the $G_{1}$ cyclin CLN3 to modulate cell fate in budding yeast. Genes Dev 15: 28032808.

Georgi AB, Stukenberg PT, Kirschner MW. 2002. Timing of events in mitosis. Curr Biol 12: 105-114.

Ginzberg MB, Kafri R, Kirschner MW. 2015. On being the right (cell) size. Science 348: 1245075.

Godin M, Delgado FF, Son S, Grover WH, Bryan AK, Tzur A, Jorgensen P, Payer K, Grossman AD, Kirschner MW, et al. 2010. Using buoyant mass to measure the growth of single cells. Nat Methods 7: 387-390.

Goranov AI, Cook M, Ricicova M, Ben-Ari G, Gonzalez C, Hansen C, Tyers M, Amon A. 2009. The rate of cell growth is governed by cell cycle stage. Genes Dev 23: $1408-1422$.

Gregory TR. 2000. Nucleotypic effects without nuclei: Genome size and erythrocyte size in mammals. Genome 43: 895-901.

Guthrie S. 2007. Patterning and axon guidance of cranial motor neurons. Nat Rev Neurosci 8: 859-871.

Hachet O, Berthelot-Grosjean M, Kokkoris K, Vincenzetti V, Moosbrugger J, Martin SG. 2011. A phosphorylation cycle shapes gradients of the DYRK family kinase Pom1 at the plasma membrane. Cell 145: 1116-1128.

Harvey SL, Kellogg DR. 2003. Conservation of mechanisms controlling entry into mitosis: Budding yeast weel delays entry into mitosis and is required for cell size control. Curr Biol 13: 264-275.

Hill NS, Kadoya R, Chattoraj DK, Levin PA. 2012. Cell size and the initiation of DNA replication in bacteria. PLoS Genet 8: e1002549.

Howell AS, Lew DJ. 2012. Morphogenesis and the cell cycle. Genetics 190: 51-77.

Irle T, Schierenberg E. 2002. Developmental potential of fused Caenorhabditis elegans oocytes: Generation of giant and twin embryos. Dev Genes Evol 212: 257-266.

Jevtic P, Levy DL. 2015. Nuclear size scaling during Xenopus early development contributes to midblastula transition timing. Curr Biol 25: 45-52.

Johnston GC. 1977. Cell size and budding during starvation of the yeast Saccharomyces cerevisiae. J Bacteriol 132: $738-739$.

Jorgensen P, Tyers M. 2004. How cells coordinate growth and division. Curr Biol 14: R1014-R1027.

Jorgensen P, Nishikawa JL, Breitkreutz BJ, Tyers M. 2002. Systematic identification of pathways that couple cell growth and division in yeast. Science 297: 395-400.
Jun S, Taheri-Araghi S. 2015. Cell-size maintenance: Universal strategy revealed. Trends Microbiol 23: 4-6.

Justman QA, Serber Z, Ferrell JE Jr, El-Samad H, Shokat KM. 2009. Tuning the activation threshold of a kinase network by nested feedback loops. Science 324: 509-512.

Kafri R, Levy J, Ginzberg MB, Oh S, Lahav G, Kirschner MW. 2013. Dynamics extracted from fixed cells reveal feedback linking cell growth to cell cycle. Nature 494: 480-483.

Kaguni JM. 2006. DnaA: Controlling the initiation of bacterial DNA replication and more. Annu Rev Microbiol 60: 351-375.

Kitagawa R, Mitsuki H, Okazaki T, Ogawa T. 1996. A novel DnaA protein-binding site at $94.7 \mathrm{~min}$ on the Escherichia coli chromosome. Mol Microbiol 19: 1137-1147.

Koivomagi M, Valk E, Venta R, Iofik A, Lepiku M, Balog ER, Rubin SM, Morgan DO, Loog M. 2011. Cascades of multisite phosphorylation control Sicl destruction at the onset of S phase. Nature 480: 128-131.

Kwon CH, Zhu X, Zhang J, Knoop LL, Tharp R, Smeyne RJ, Eberhart CG, Burger PC, Baker SJ. 2001. Pten regulates neuronal soma size: A mouse model of Lhermitte-Duclos disease. Nat Genet 29, 404-411.

* Levin PA, Angert ER. 2015. Small but mighty: Cell size and bacteria. Cold Spring Harb Perspect Biol doi: 10.1101/ cshperspect.a019216.

Liu X, Wang X, Yang X, Liu S, Jiang L, Qu Y, Hu L, Ouyang Q, Tang C. 2015. Reliable cell cycle commitment in budding yeast is ensured by signal integration. eLife doi: 10.7554/eLife.03977.

Lobner-Olesen A, Skarstad K, Hansen FG, von Meyenburg K, Boye E. 1989. The DnaA protein determines the initiation mass of Escherichia coli K-12. Cell 57: 881-889.

Luef B, Frischkorn KR, Wrighton KC, Holman H-YN, Birarda G, Thomas BC, Singh A, Williams KH, Siegerist CE, Tringe SG, et al. 2015. Diverse uncultivated ultra-small bacterial cells in groundwater. Nat Commun doi: 10.1038/ ncomms7372.

* Marshall WF. 2015. Subcellular size. Cold Spring Harb Perspect Biol 7: a019059.

Martin SG, Berthelot-Grosjean M. 2009. Polar gradients of the DYRK-family kinase Pom 1 couple cell length with the cell cycle. Nature 459: 852-856.

Masui Y, Wang P. 1998. Cell cycle transition in early embryonic development of Xenopus laevis. Biol Cell 90: 537548.

Mayer VW, Goin CJ, Arras CA, Taylor-Mayer RE. 1992. Comparison of chemically induced chromosome loss in a diploid, triploid, and tetraploid strain of Saccharomyces cerevisiae. Mutat Res 279: 41-48.

McNulty JJ, Lew DJ. 2005. Swelp responds to cytoskeletal perturbation, not bud size, in S. cerevisiae. Curr Biol 15: 2190-2198.

Miller ME, Cross FR. 2000. Distinct subcellular localization patterns contribute to functional specificity of the $\mathrm{Cln} 2$ and Cln 3 cyclins of Saccharomyces cerevisiae. Mol Cell Biol 20: $542-555$.

Mitchison JM. 2003. Growth during the cell cycle. Int Rev Cytol 226: 165-258.

Monds RD, Lee TK, Colavin A, Ursell T, Quan S, Cooper TF, Huang KC. 2014. Systematic perturbation of cytoskeletal 
function reveals a linear scaling relationship between cell geometry and fitness. Cell Rep 9: 1528-1537.

Mortimer RK. 1958. Radiobiological and genetic studies on a polyploid series (haploid to hexaploid) of Saccharomyces cerevisiae. Radiat Res 9: 312-326.

Moseley JB, Mayeux A, Paoletti A, Nurse P. 2009. A spatial gradient coordinates cell size and mitotic entry in fission yeast. Nature 459: 857-860.

Murphy CM, Michael WM. 2013. Control of DNA replication by the nucleus/cytoplasm ratio in Xenopus. J Biol Chem 288: 29382-29393.

Nair DR, D'Ausilio CA, Occhipinti P, Borsuk ME, Gladfelter AS. 2010. A conserved $G_{1}$ regulatory circuit promotes asynchronous behavior of nuclei sharing a common cytoplasm. Cell Cycle 9: 3771-3779.

Neufeld TP, de la Cruz AF, Johnston LA, Edgar BA. 1998 Coordination of growth and cell division in the Drosophila wing. Cell 93: 1183-1193.

Neumann FR, Nurse P. 2007. Nuclear size control in fission yeast. J Cell Biol 179: 593-600.

Newman JR, Ghaemmaghami S, Ihmels J, Breslow DK, Noble M, DeRisi JL, Weissman JS. 2006. Single-cell proteomic analysis of $S$. cerevisiae reveals the architecture of biological noise. Nature 441: 840-846.

Newport J, Kirschner M. 1982a. A major developmenta transition in early Xenopus embryos. I: characterization and timing of cellular changes at the midblastula stage. Cell 30: 675-686.

Newport J, Kirschner M. 1982b. A major developmental transition in early Xenopus embryos. II: Control of the onset of transcription. Cell 30: 687-696.

Oliva A, Rosebrock A, Ferrezuelo F, Pyne S, Chen H, Skiena S, Futcher B, Leatherwood J. 2005. The cell cycle-regulated genes of Schizosaccharomyces pombe. PLoS Biol 3: e225.

Osella M, Nugent E, Cosentino Lagomarsino M. 2014. Concerted control of Escherichia coli cell division. Proc Natl Acad Sci 111: 3431-3435.

Palenik B, Grimwood J, Aerts A, Rouze P, Salamov A, Putnam N, Dupont C, Jorgensen R, Derelle E, Rombauts S, et al. 2007. The tiny eukaryote Ostreococcus provides genomic insights into the paradox of plankton speciation. Proc Natl Acad Sci 104: 7705-7710.

Pan KZ, Saunders TE, Flor-Parra I, Howard M, Chang F 2014. Cortical regulation of cell size by a sizer cdr2p. eLife 3: $\mathrm{e} 02040$

Payne JL, Groves JR, Jost AB, Nguyen T, Moffitt SE, Hill TM Skotheim JM. 2012. Late paleozoic fusulinoidean gigantism driven by atmospheric hyperoxia. Evolution 66: 2929-2939.

Payne JL, Jost AB, Wang SC, Skotheim JM. 2013. A shift in the long-term mode of foraminiferan size evolution caused by the end-Permian mass extinction. Evolution 67: 816-827.

* Penzo-Méndez AI, Stanger BZ. 2015. Organ size regulation in mammals. Cold Spring Harb Perspect Biol doi: 10.1101/cshperspect.a019240.

Pomerening JR, Sontag ED, Ferrell JE Jr. 2003. Building a cell cycle oscillator: Hysteresis and bistability in the activation of Cdc2. Nat Cell Biol 5: 346-351.
* Reber S, Goehring NW. 2015. Intracellular scaling mechanisms. Cold Spring Harb Perspect Biol doi: 10.1101/ cshperspect.a019067.

* Roth G, Walkowiak W. 2015. The influence of genome and cell size on brain morphology in amphibians. Cold Spring Harb Perspect Biol doi: 10.1101/cshperspect.a019075.

Saunders TE, Pan KZ, Angel A, Guan Y, Shah JV, Howard M, Chang F. 2012. Noise reduction in the intracellular pomlp gradient by a dynamic clustering mechanism. Dev Cell 22: 558-572.

Schmoller K, Turner JJ, Koivomagi M, Skotheim JM. 2015. Dilution of the cell cycle inhibitor Whi5 controls budding yeast cell size. Nature (in press).

Schulz HN, Brinkhoff T, Ferdelman TG, Marine MH, Teske A, Jorgensen BB. 1999. Dense populations of a giant sulfur bacterium in Namibian shelf sediments. Science 284: 493-495.

Sha W, Moore J, Chen K, Lassaletta AD, Yi CS, Tyson JJ, Sible JC. 2003. Hysteresis drives cell-cycle transitions in Xenopus laevis egg extracts. Proc Natl Acad Sci 100: 975-980.

Skotheim JM, Di Talia S, Siggia ED, Cross FR. 2008. Positive feedback of $G_{1}$ cyclins ensures coherent cell cycle entry. Nature 454: 291-296.

Son S, Tzur A, Weng Y, Jorgensen P, Kim J, Kirschner MW, Manalis SR. 2012. Direct observation of mammalian cell growth and size regulation. Nat Methods 9: 910-912.

Spellman PT, Sherlock G, Zhang MQ, Iyer VR, Anders K, Eisen MB, Brown PO, Botstein D, Futcher B. 1998. Comprehensive identification of cell cycle-regulated genes of the yeast Saccharomyces cerevisiae by microarray hybridization. Mol Biol Cell 9: 3273-3297.

Sung Y, Tzur A, Oh S, Choi W, Li V, Dasari RR, Yaqoob Z, Kirschner MW. 2013. Size homeostasis in adherent cells studied by synthetic phase microscopy. Proc Natl Acad Sci 110: $16687-16692$.

Sveiczer A, Novak B, Mitchison JM. 1996. The size control of fission yeast revisited. J Cell Sci 109: 2947-2957.

Taheri-Araghi S, Bradde S, Sauls JT, Hill NS, Levin PA, Paulsson J, Vergassola M, Jun S. 2015. Cell-size control and homeostasis in bacteria. Curr Biol 25: 385-391.

Tautvydas KJ. 1976. Evidence for chromosome endoreduplication in Eudorina californica, a colonial alga. Differentiation 5: 35-42.

Teather RM, Collins JF, Donachie WD. 1974. Quantal behavior of a diffusible factor which initiates septum formation at potential division sites in Escherichia coli. J Bacteriol 118: 407-413.

Tokiwa G, Tyers M, Volpe T, Futcher B. 1994. Inhibition of $\mathrm{G}_{1}$ cyclin activity by the Ras/cAMP pathway in yeast. Nature 371: 342-345.

Traas J, Hulskamp M, Gendreau E, Hofte H. 1998. Endoreduplication and development: Rule without dividing? Curr Opin Plant Biol 1: 498-503.

Turner JJ, Ewald JC, Skotheim JM. 2012. Cell size control in yeast. Curr Biol 22: R350-R359.

Tyers M, Tokiwa G, Futcher B. 1993. Comparison of the Saccharomyces cerevisiae $\mathrm{G}_{1}$ cyclins: $\mathrm{Cln} 3$ may be an upstream activator of $\mathrm{Cln} 1, \mathrm{Cln} 2$ and other cyclins. EMBO J 12: $1955-1968$.

Tyson JJ, Diekmann O. 1986. Sloppy size control of the cell division cycle. J Theor Biol 118: 405-426. 
A.A. Amodeo and J.M. Skotheim

Tyson JJ, Hannsgen KB. 1985. The distributions of cell size and generation time in a model of the cell cycle incorporating size control and random transitions. $J$ Theor Biol 113: $29-62$.

Verges E, Colomina N, Gari E, Gallego C, Aldea M. 2007. Cyclin $\mathrm{Cln} 3$ is retained at the ER and released by the J chaperone Ydj1 in late $\mathrm{G}_{1}$ to trigger cell cycle entry. Mol Cell 26: 649-662.

Wallace RA, Misulovin Z, Etkin LD. 1981. Full-grown oocytes from Xenopus laevis resume growth when placed in culture. Proc Natl Acad Sci 78: 3078-3082.

Wang H, Gari E, Verges E, Gallego C, Aldea M. 2004. Recruitment of $\mathrm{Cdc} 28$ by Whi3 restricts nuclear accumulation of the $\mathrm{G}_{1}$ cyclin-Cdk complex to late $\mathrm{G}_{1}$. EMBO J 23: $180-190$.

Watanabe N, Ishihara T, Ohshima Y. 2007. Mutants carrying two SMA mutations are super small in the nematode C. elegans. Genes Cells 12: 603-609.

Wheals AE. 1982. Size control models of Saccharomyces cerevisiae cell proliferation. Mol Cell Biol 2: 361-368.

Whitfield ML, Sherlock G, Saldanha AJ, Murray JI, Ball CA, Alexander KE, Matese JC, Perou CM, Hurt MM, Brown PO, et al. 2002. Identification of genes periodically expressed in the human cell cycle and their expression in tumors. Mol Biol Cell 13: 1977-2000.
Wilson EB. 1926. The cell in development and heredity, pp. 916-923. MacMillan, New York.

Wood E, Nurse P. 2013. Pom1 and cell size homeostasis in fission yeast. Cell Cycle 12: 3228-3236.

Wu CY, Rolfe PA, Gifford DK, Fink GR. 2010. Control of transcription by cell size. PLoS Biol 8: e1000523.

Yahya G, Parisi E, Flores A, Gallego C, Aldea M. 2014. A Whi7-anchored loop controls the $\mathrm{G}_{1} \mathrm{Cdk}$-cyclin complex at start. Mol Cell 53: 115-126.

Yamagishi M, Ito E, Matsuo R. 2011. DNA endoreplication in the brain neurons during body growth of an adult slug. J Neurosci 31: 5596-5604.

Yang X, Lau KY, Sevim V, Tang C. 2013. Design principles of the yeast $\mathrm{G}_{1} / \mathrm{S}$ switch. PLoS Biol 11: e1001673.

Zapata J, Dephoure N, Macdonough T, Yu Y, Parnell EJ, Mooring M, Gygi SP, Stillman DJ, Kellogg DR. 2014. PP2ARts1 is a master regulator of pathways that control cell size. J Cell Biol 204: 359-376.

Zhao H, Dreses-Werringloer U, Davies P, Marambaud P. 2008. Amyloid- $\beta$ peptide degradation in cell cultures by mycoplasma contaminants. BMC Res Notes 1: 38 .

Zielke N, Edgar BA, DePamphilis ML. 2013. Endoreplication. Cold Spring Harb Perspect Biol 5: a012948. 


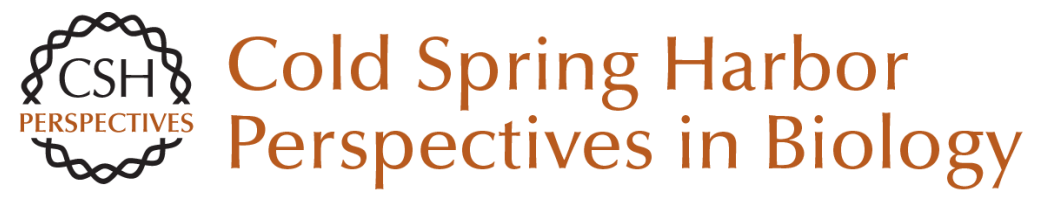

\section{Cell-Size Control}

Amanda A. Amodeo and Jan M. Skotheim

Cold Spring Harb Perspect Biol 2016; doi: 10.1101/cshperspect.a019083 originally published online August 7, 2015

Subject Collection Size Control in Biology: From Organelles to Organisms

Cell-Size Control

Amanda A. Amodeo and Jan M. Skotheim

Indeterminate Growth: Could It Represent the

Ancestral Condition?

Iswar K. Hariharan, David B. Wake and Marvalee H. Wake

The Systemic Control of Growth Laura Boulan, Marco Milán and Pierre Léopold

Genome Biology and the Evolution of Cell-Size Diversity

Rachel Lockridge Mueller

Size Scaling of Microtubule Assemblies in Early Xenopus Embryos

Timothy J. Mitchison, Keisuke Ishihara, Phuong Nguyen, et al.

The Influence of Genome and Cell Size on Brain Morphology in Amphibians Gerhard Roth and Wolfgang Walkowiak

The Opposing Actions of Target of Rapamycin and AMP-Activated Protein Kinase in Cell Growth Control

Sravanth K. Hindupur, Asier González and Michael N. Hall

Small but Mighty: Cell Size and Bacteria

Petra Anne Levin and Esther R. Angert
Mechanical Forces and Growth in Animal Tissues Loïc LeGoff and Thomas Lecuit

Biological Scaling Problems and Solutions in

Amphibians

Daniel L. Levy and Rebecca Heald

Intracellular Scaling Mechanisms Simone Reber and Nathan W. Goehring

Growing an Embryo from a Single Cell: A Hurdle in Animal Life Patrick H. O'Farrell

Organ-Size Regulation in Mammals Alfredo I. Penzo-Méndez and Ben Z. Stanger

Size Control in Plants--Lessons from Leaves and Flowers Hjördis Czesnick and Michael Lenhard

Nuclear DNA Content Varies with Cell Size across Human Cell Types

James F. Gillooly, Andrew Hein and Rachel

Damiani

Subcellular Size

Wallace F. Marshall

For additional articles in this collection, see http://cshperspectives.cshlp.org/cgi/collection/

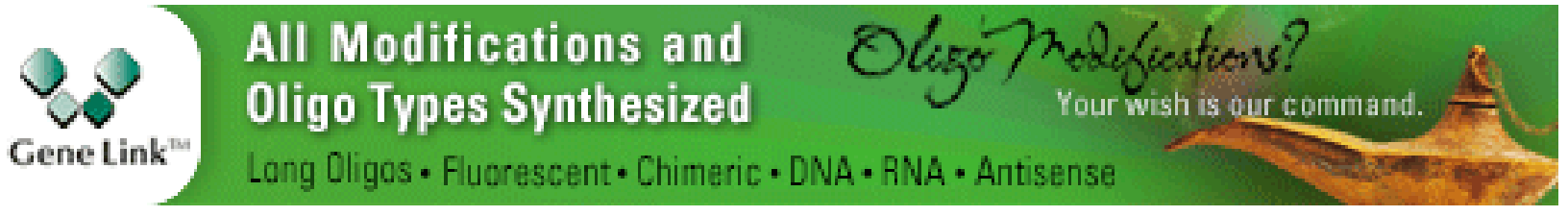

Copyright @ 2016 Cold Spring Harbor Laboratory Press; all rights reserved 